\title{
Polyp dimorphism and functional, sequential hermaphroditism in the soft coral Heteroxenia fuscescens (Octocorallia)
}

\author{
Yair Achituv', Yehuda Benayahu ${ }^{2}$ \\ ${ }^{1}$ Department of Life Sciences, Bar-Ilan University, Ramat-Gan 52900, Israel \\ ${ }^{2}$ Department of Zoology, George S. Wise Faculty oi Life Sciences, Tel-Aviv University, Ramal-Aviv, Tel-Aviv 69978, Israel
}

\begin{abstract}
Heteroxenia fuscescens is a dimorphic alcyonacean composed of autozooids and siphonozooids. The appearance of siphonozooids in the colony is size-dependent and their density gradually increases with colony diameter. Colonies in all size groups are simultaneous hermaphrodites and bear male and female gonads in their autozooids. H. fuscescens exhibits a size-dependent, functional, sequential hermaphroditism in which mature monomorphic colonies produce only ripe sperm while dimorphic ones produce mainly eggs and relatively few sperm. Mature dimorphic colonies demonstrate a spatial segregation of reproductive products along the gastrovascular cavity. Germinative activity and extensive gonad growth of both sexes are carried out below the anthocodiae, mature eggs fill most of the gastrovascular cavity and fertilized eggs are very often observed in its basal part. Gametogenesis begins at a remarkably early age. However the size-dependent appearance of siphonozooids serves as a threshold, below which maturation and fertilization of eggs cannot occur. Reproductive effort in $H$. fuscescens is age-specific and exhibits an optimal allocation of energetic reserves which relates to polyp dimorphism.
\end{abstract}

\section{INTRODUCTION}

Dimorphism of polyps occurs in several Octocorallia in which the colonies are composed of 2 kinds of polyps: autozooids and siphonozooids (Hyman 1940). Autozooids are distinguished by the possession of 8 pinnate tentacles combined with 8 septa attached to the pharynx. Siphonozooids, by comparison, are greatly reduced in size, and their tentacles are rudimentary (Hyman 1940). The siphonozooids also have a highly developed siphonoglyph along with 2 asulcal filaments which drive a water current through the colony (Bayer 1973). Siphonozooids are characteristic of large, fleshy octocorals, and they bear gonads infrequently. All Pennatulacea are dimorphic with gonads developed in their autozooids only (Hyman 1940). In the Gorgonacea, dimorphism is very rare and occurs only in the Scleraxonian families Corallidae and Paragorgidae. In Corallium rubrum the gonads are produced by the autozooids, while in Paragorgia spp. both autozooids and siphonozooids bear gonads (Bayer 1973)

Among the Alcyonacea dimorphism displays a wide range of colonial organization in the families Alcyoniidae and Xeniidae. The Alcyoniidae contains several dimorphic genera, i.e. Bathyalcyon, Carotalcyon, Anthomastus, Malacacanthus, Minabea, Acrophyton, Sarcophyton and Lobophytum (Verseveldt \& Bayer 1988). The gonads of Bathyalcyon robustum are located in the siphonozooids, while its single giant autozooid is sterile (Bock 1938). Minabea robusta bears gonads in both types of polyps (Utinomi \& Imahara 1976). The widely distributed coral-reef species of Lobophytum and Sarcophyton have gonads only in their autozooids (Yamazato et al. 1981, Benayahu \& Loya 1986). Dimorphism in the Xeniidae has been a subject of controversy for a long period (Hickson 1931, Gohar 1940), however, it is agreed that the genera Fungulus and Heteroxenia are dimorphic (Bayer 1981). Heteroxenia species bear gonads in the autozooids (Gohar 1940, Benayahu et al. 1989). A recent study demonstrated that the developing planulae of Heteroxenia fuscescens gain maturity while brooded between the siphonozooids (Benayahu et al. 1989). H. fuscescens is hermaphrodite (Gohar 1940) with a year-round planulation on Eilat reefs (Benayahu 1990). 
In this study we examine dimorphism in relation to colony size in a population of Heteroxenia fuscescens. We describe the relationship between colony size, reproductive condition and gronad development. This is the first account to deal with age-dependent functional sexuality in a dimorphic octocoral and also the first to follow changes in reproductive pattern with increasing colony size.

\section{MATERIALS AND METHODS}

Colonies of Heteroxenia fuscescens were collected on Eilat reefs, Red Sea, during August 1985 to August 1987. Each month 6 to 8 dimorphic colonies were sampled randomly, between 2 and $6 \mathrm{~m}$ depth. In addition, every 4 to 5 mo, monomorphic and dimorphic colonies of various sizes were collected, including juveniles with a diameter of $<5 \mathrm{~mm}$. The entire sample tatalled 274 colonies, which were fixed in $4 \%$ formalin in seawater. Colonies were dissected longitudinally, and the trunk diameter of each measured to the nearest $\mathrm{mm}$. They were then examined under a binocular stereoscope for the presence of dimorphic polyps and gonads in their polyp cavities. From each size group (see below), gonads were taken from 5 colonies for histological sectioning. The small colonies $(<5 \mathrm{~mm}$ diameter) were totally sectioned and from larger colonies, sectors containing gonads were serially sectioned. Material for histology was then decalcified in a mixture of equal volumes of formic acid (50\%) and sodium citrate (15\%) for $20 \mathrm{~min}$. Paraplast (Monoject Scientific) sections $8 \mu \mathrm{m}$ thick were cut and stained in hematoxylin-eosin.

\section{RESULTS}

Fig. 1 presents the relationship between colony size and dimorphism in Heteroxenia fuscescens. All colonies smaller than $10 \mathrm{~mm}$ in diameter were monomorphic. The appearance of siphonozooids is size-dependent and the percentage of dimorphic colonies gradually increases with size. All examined colonies larger than $36 \mathrm{~mm}$ in diameter were dimorphic (Fig. 1). Dimorphic colonies were sampled throughout the year and their abundance indicates no annual pattern. All examined colonies of $H$. fuscescens, including the smallest ones ( $\leq 5 \mathrm{~mm}$ diameter) are simultaneously hermaphrodite and bear male and female gonads in their autozooids. The gonads are located along the 2 ventral and 4 lateral mesenteries of the polyp, except for its anthocodial part.

In the smallest examined colonies ( $\leq 5 \mathrm{~mm}$ diameter) gonads are observed as clusters of primordial germinal cells (Fig. 2A), and primordial spermaries and oocytes

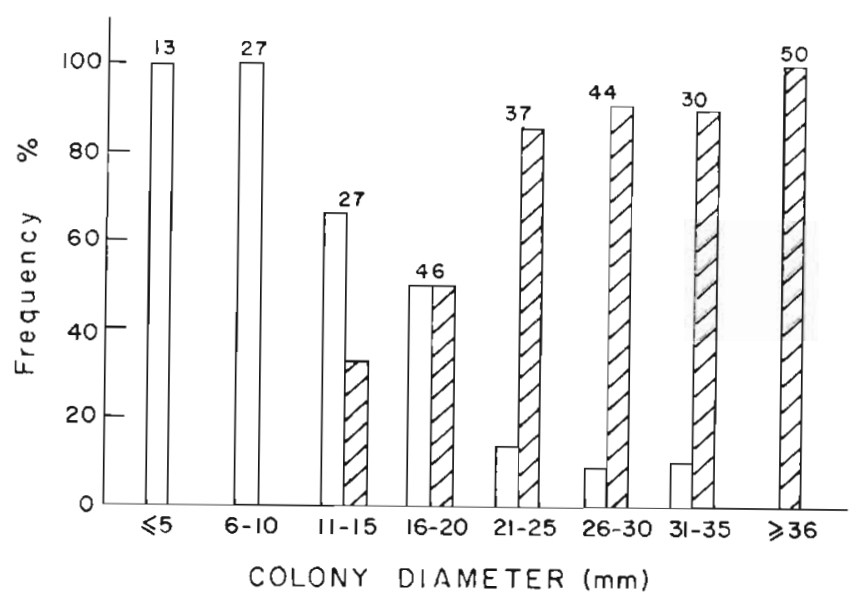

Fig. 1. Heteroxenia fuscescens. Sizes distinguished by the occurrence of monomorphic (open bars) and dimorphic (hatched bars) colonies in a randomly collected sample Number of corals measured is indicated for each size group

are occasionally found within the same genital cluster. Each of these primoridiae is attached to the mesenteries by a short pedicel and enveloped by a thin layer of mesoglea and endoderm (Fig. 2A, B). At a further developmental stage a few oocytes are surrounded by a common endodermal cell layer (Fig. 2C). During subsequent gametogenesis each oocyte or sperm sac is enveloped within separate peripheral endoderm (Fig. $2 \mathrm{D})$, and separately attached to the mesenteries.

In all monomorphic colonies ( $\geq 6 \mathrm{~mm}$ diameter), sperm sacs are dominant, while oocytes are scarce within the gastrovascular cavity (Fig. 3A). In these colonies the maximal diameter of the oocytes is $300 \mu \mathrm{m}$ and they have a darkly stained yolk (Fig. 3A). Extensive spermatogenesis in these monomorphs leads to the occurence of series of developmental stages of spermaries within a single polyp (Fig. $3 \mathrm{~A}$ to E). During initial stages the sperm sacs are uniformly filled with spermatids (Fig. 3A). At a subsequent stage the spermatogenetic columns are located at the periphery of the sperm sac, with the tail ends of mature sperm cells projecting toward the cavity (Fig. 3B). At an advanced stage some of the sperm cells are concentrated in the center of the spermary (Fig. 3C). Final sperm-sac maturation is associated with the appearance of sperm bundles within the cavity, recognized as clusters of dark stained sperm-heads and lightly stained tails (Figs. 3D, E). Sperm sac maturation is accompanied by a gradual increase in their diameter to a maximum of $350 \mu \mathrm{m}$ (Fig. 3A to E).

All dimorphic colonies are characterized by the dominance of large oocytes (700 to $800 \mu \mathrm{m}$ ) within the gastrovascular cavities (Fig. 4A). Their upper part, below the anthocodiae, contains various developmental stages of male and female gonads (Fig. 4A). The 


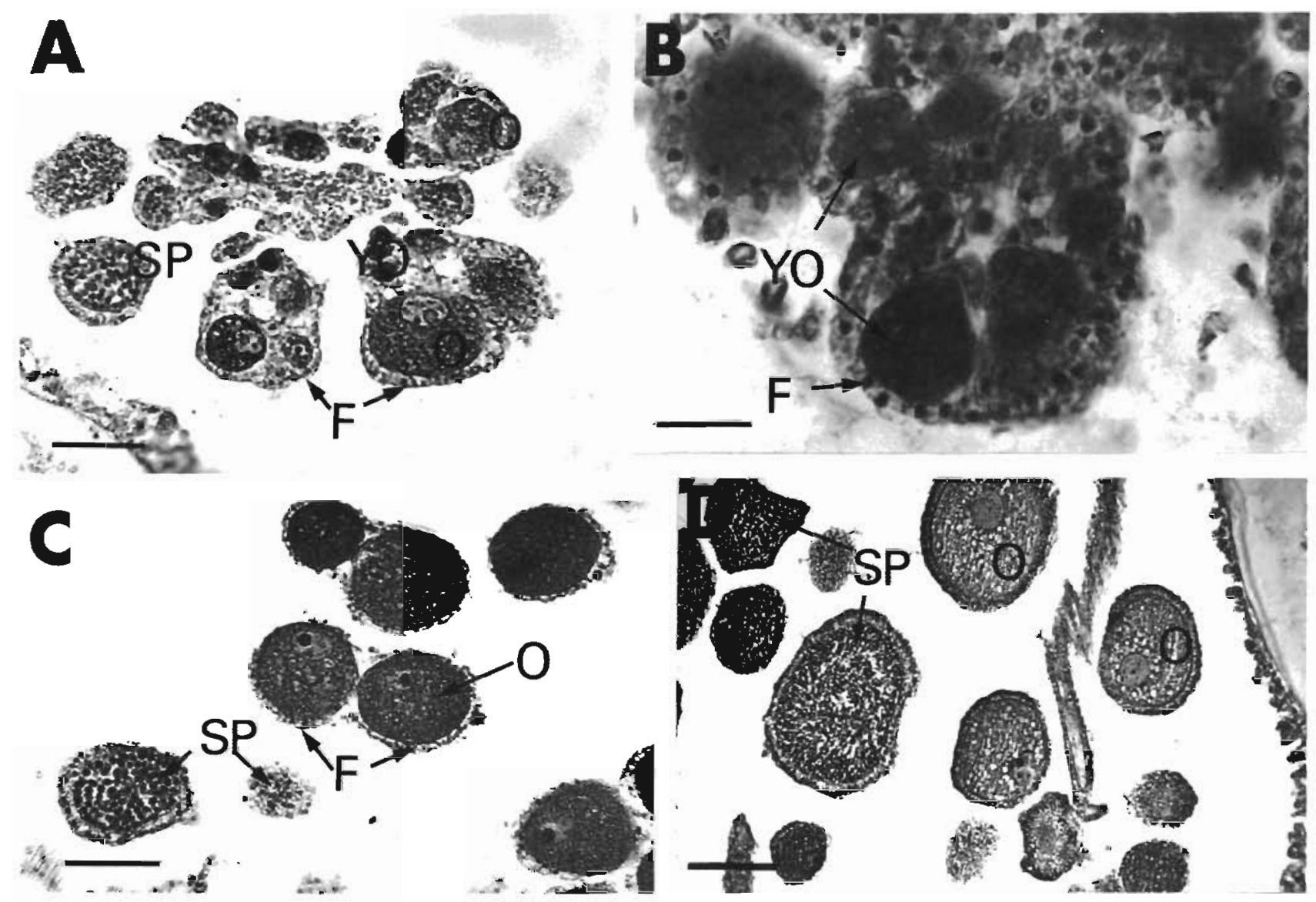

Fig. 2. Heteroxenia fuscescens. (A) Initial cluster of gonadal primordiae comprised of oocytes and spermaries. Scale bar $=25 \mu \mathrm{m}$ (B) Initial gonadal primordium with its endodermal envelope. Scale bar $=10 \mu \mathrm{m}$. (C) Young oocytes within a common envelope Scale bar $=50 \mu \mathrm{m}$. (D) Young gonads separately surrounded with endodermal cell layer. Scale bar $=50 \mu \mathrm{m}$. F: follicular layer; $\mathrm{O}$ oocyte; SP: spermary; YO: young oocyte

female gonads are comprised of a wide size-range of oogenic stages with a gradual increase in their diameter toward the basal polyp-cavity (Fig. 4A). The follicular, endodermal layer and the mesoglea surrounding of the oocytes become thicker throughout oogenesis (Fig. $4 \mathrm{~B}$ to $\mathrm{D}$ ), reaching $30 \mu \mathrm{m}$ in mature eggs. In addition, below the anthocodiae, groups of spermaries are found among oocytes (Fig. 4A, B) and occasionally mature spermaries are observed in this part of the autozooid. Some islets of spermaries are located between mature oocytes (Fig. 4A, C, D) which are probably remains of previous spawned sperm sacs.

Table 1 summarizes the location and distribution of male and female gonads and embryos in the autozooids of dimorphic colonies. These results demonstrate a distinct spatial segregation of reproductive products along the gastrovascular cavity. Germinative activity and extensive gonad growth of both sexes takes place below the anthocodiae. Mature oocytes fill the major part of the gastrovascular cavity. In addition, fertilized eggs and early embryogenic stages are very often observed in the basal part of the autozooids (Benayahu et al. 1989).

\section{DISCUSSION}

Early investigators considered polyp dimorphism among Octocorallia to be a major taxonomic feature (Hickson 1931, Gohar 1940). Later, the physiological role of siphonozooids was recognized (Bayer 1973 1981). In the dimorphic soft coral Heteroxenia fuscescens, immature planulae are released externally into intersiphonozooid spaces where they mature, and therefore dimorphism in this coral is essential for brood care. The reproductive condition of $H$. fuscescens during its monomorphic and dimorphic life phases is summarized in Fig. 5, indicating a distinct simultaneous hermaphroditism in all size groups. Settlement of $H$ fuscescens on artificial substrata at Eilat indicates an approximate annual increment in colony diameter of 

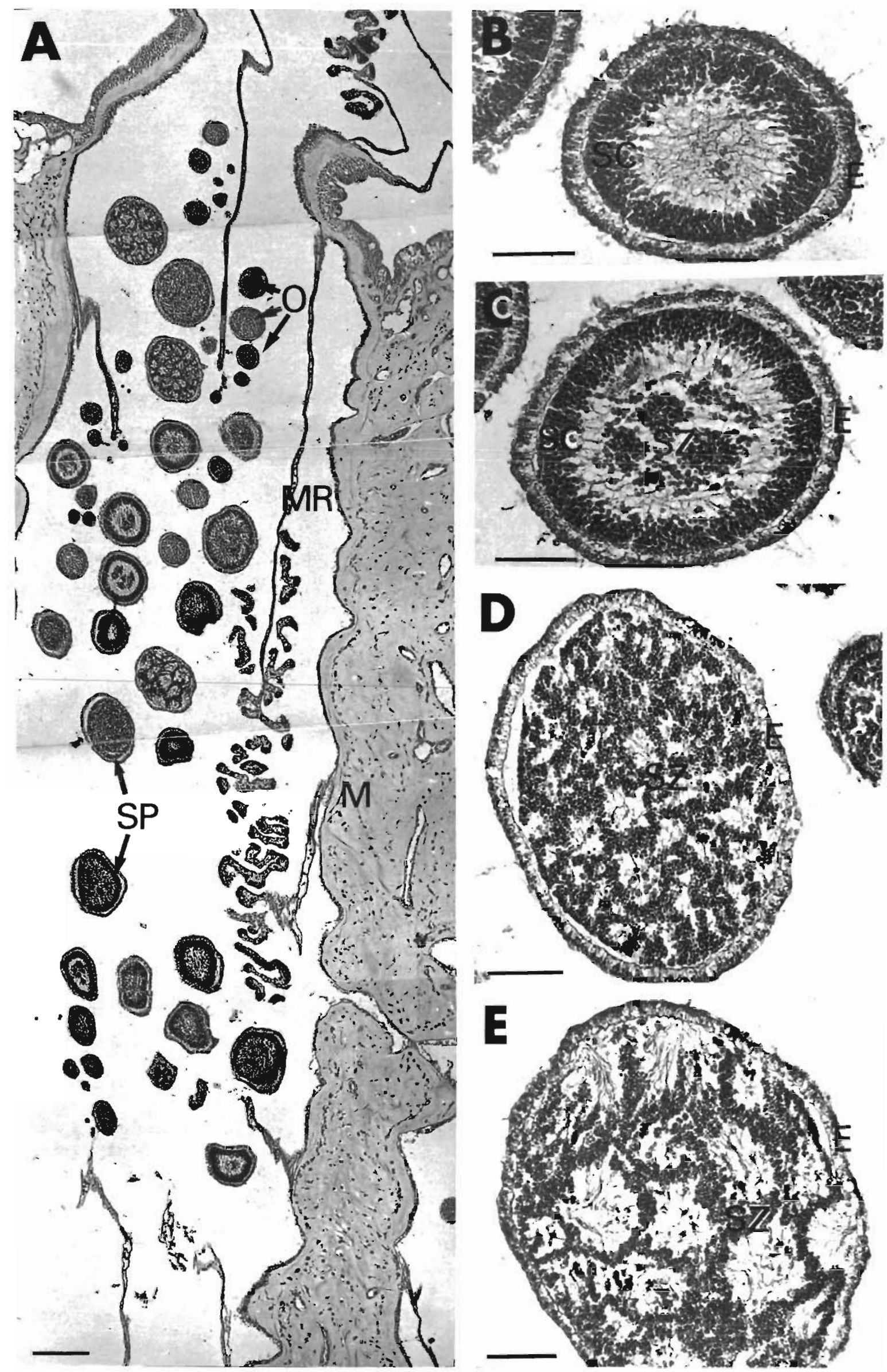
Table 1. Heteroxenia fuscescens. Location of female and male gonads and embryos along the gastrovascular cavities of dimorphic colonies

\begin{tabular}{|llc|}
\hline Location & Genital products & $\begin{array}{c}\text { Sizo range } \\
\text { (length in } \mu \mathrm{m} \text { ) }\end{array}$ \\
\hline Upper & Spermares & $<50-350$ \\
Middle & Oocytes & $<50-350$ \\
Basal & Oocytes & $400-800$ \\
& Oocytes & $400-800$ \\
& Embryos & $800-1000$ \\
\hline
\end{tabular}

$5 \mathrm{~mm}$ (Benayahu unpubl. data). Thus, gonad initiation is performed at an extremely early age, less than $1 \mathrm{yI}$ (Figs. 1 and 5). Most colonies of $H$. fuscescens are dimorphic at ca 4 yr (Fig. 1). Hence, their dimorphism is a size-dependent feature, a finding which contradicts both Cylkowski's (1911) results which did not display such a relationship, and Gohar's (1940) claim of the periodical appearance of siphonozooids. Available data indicate that all size classes of Sarcophyton glaucum and Lobophytum pauciflorum in the Red Sea are dimorphic (Benayahu \& Loya 1986, Benayahu unpubl. data). Additional studies are required in order to generalize about the relationships between age and occurrence of siphonozooids in other dimorphic octocorals.

The reproductive pattern of Heteroxenia fuscescens involves gametogenesis of both male and female gonads at a remarkably early age (Fig. 5). The reproductive features are further characterized by functional, sequential hermaphroditism, i.e. mature monomorphic colonies produce only ripe sperm while dimorphic ones produce mainly eggs, along with some sperm. Gohar (1940) stated that one sex does not mature before the other. In contrast, our results demonstrate temporal segregation of gonadal maturation in this species. The completion of oogenic cycles in monomorphic colonies would produce mature oocytes at a stage when the colonies are not yet structurally capable of brooding planulae because they lack siphonozooids. We suggest that the size-dependent appearance of siphonozooids in $H$. fuscescens is a developmental threshold, below which egg maturation, fertilization and embryogenesis cannot occur.

Organisms exhibit age-dependent trade-off between growth and reproduction (Harvell \& Grossberg 1988).
These processes are often described as competing biological functions that are derived from limited energy resources (Chornesky \& Peters 1987). The reproductive features of Heteroxenia fuscescens are associated with colony size (Fig 5) and may reflect energetic constraints. During the life phases of this soft coral, energy is initially allocated for increasing colonytrunk size and the number of autozooids, and subsequently for development of siphonozooids. The high energy expenditure for this somatic growth most probably restrains the proportion of total available resources allocated for reproduction (Samson \& Werk 1986). Hence, $H$. fuscescens exhibits the size-dependent tactics of functional, sequential hermaphroditism and delayed egg maturation. In addition, the large oocytes of $H$. fuscescens demand spacious gastrovascular cavities and thus it is advantageous to postpone their ripening until a large colony size is attained.

Autozooids of Heteroxenia fuscescens are functionally autotrophic due to their dense populations of endocytobiotic dinoflagellates (zooxanthellae), and the utilization of dissolved organic matter (DOM) from ambient seawater (Schlichter \& Kremer 1985). We suggest that the appearance of siphonozooids increases internal-colony surface-area for the uptake of DOM. This contributes considerably to higher energy assimilation which enables allocation of the required energy for planulae development.

Complex interactions between intrinsic factors (size, age, and physiological conditions) and extrinsic factors (environmental conditions) regulate the timing of sexual maturity (Harvell \& Grosberg 1988). However, the temporal reproductive features of Heteroxenia fuscescens appear to be related predominantly to colony organization. Polyp dimorphism serves as a major cue which determines its sexual pattern, and accelerates egg maturation and the subsequent brooding of planulae. It is proposed that reproductive effort in $H$. fuscescens is age-specific, and that the soft coral exhibits an optimal allocation of resources which is related to polyp dimorphism.

Acknowledgements. We are grateful to Dr N. E. Chadwick for improving this manuscript. We thank the staff of the InterUniversity Institute of Ejlat for their kind hospitality. This study was partly supported by a grant provided by the Basic Research Foundation administered by the Israel Academy of Sciences to $Y$ Benayahu.

Fig. 3. Heteroxenia fuscescens. Longitudinal section through autozooid cavity, and gonads of a large monomorphic colony. (A) Arrangement of male and female gonads. Scale bar $=200 \mu \mathrm{m}$. (B to E) Various developmental stages of sperm sacs within a large monomorphic colony. Scale bar $=100 \mu \mathrm{m}$. E: envelope cells; M: mesoglea; MR: mesentery; O: oocyte; SC: spermatogenetic columns; SP: spermary; SZ: spermatozoons 

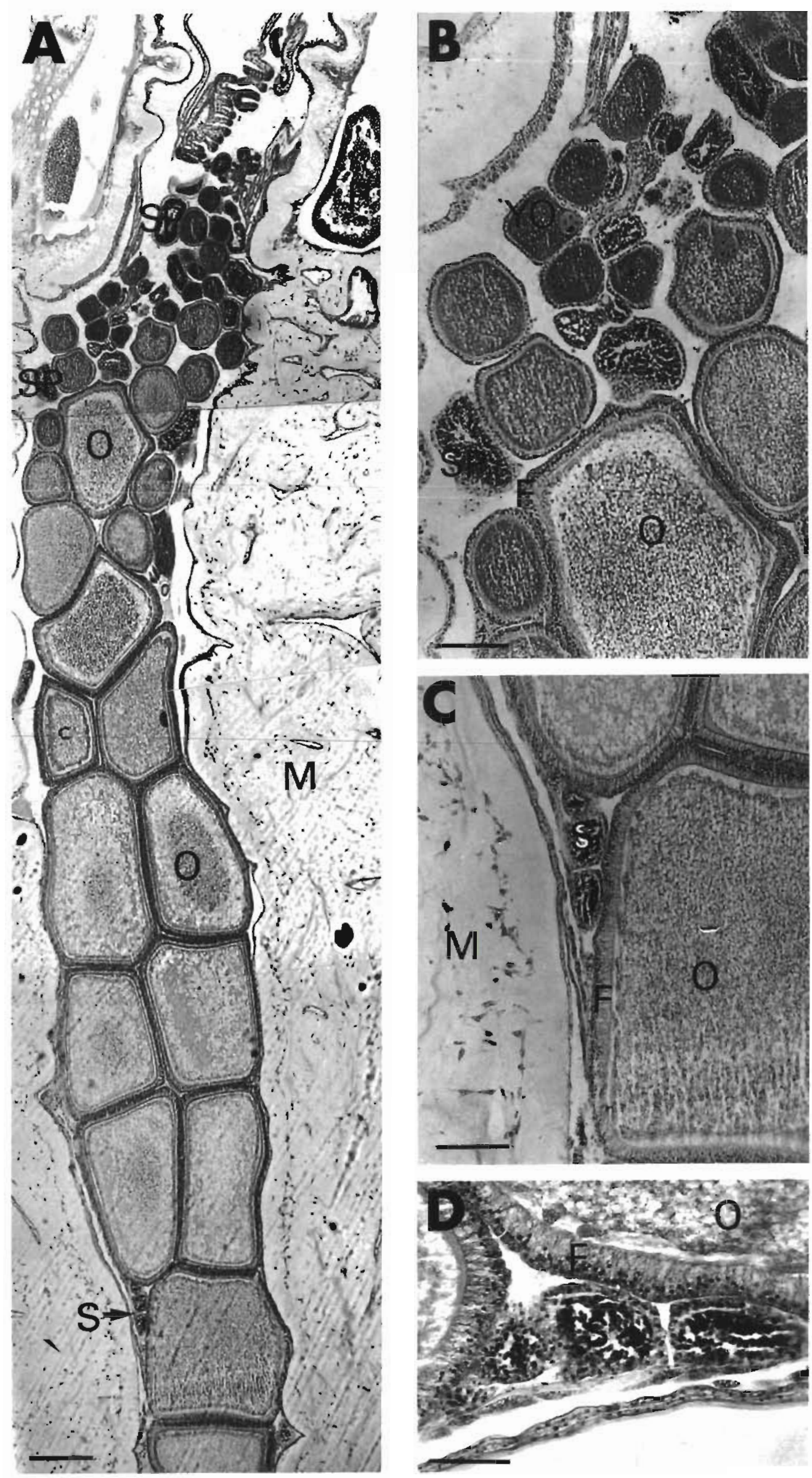

Fig. 4. Heteroxenia fuscescens. Longitudinal section through autozooid cavity and gonads of a mature, dimorphic colony. (A) Arrangement of male and female gonads. Scale bar = $200 \mu \mathrm{m}$. (B) Upper part of autozooid cavity with various developmental stages of male and female gonads Scale bar $=100 \mu \mathrm{m} . \quad(\mathrm{C}$ and D) Mature oocytes and remains of previously spawned sperm-sacs. Scale bar $\mathrm{C}=100$ um. $\mathrm{D}=$ $50 \mu \mathrm{m}$. F: follicular layer: M: mesoglea; $\mathrm{O}$ : oocyte; $\mathrm{S}$ : sperm islets; SP: spermary; $\mathrm{YO}$ : young oocyte 


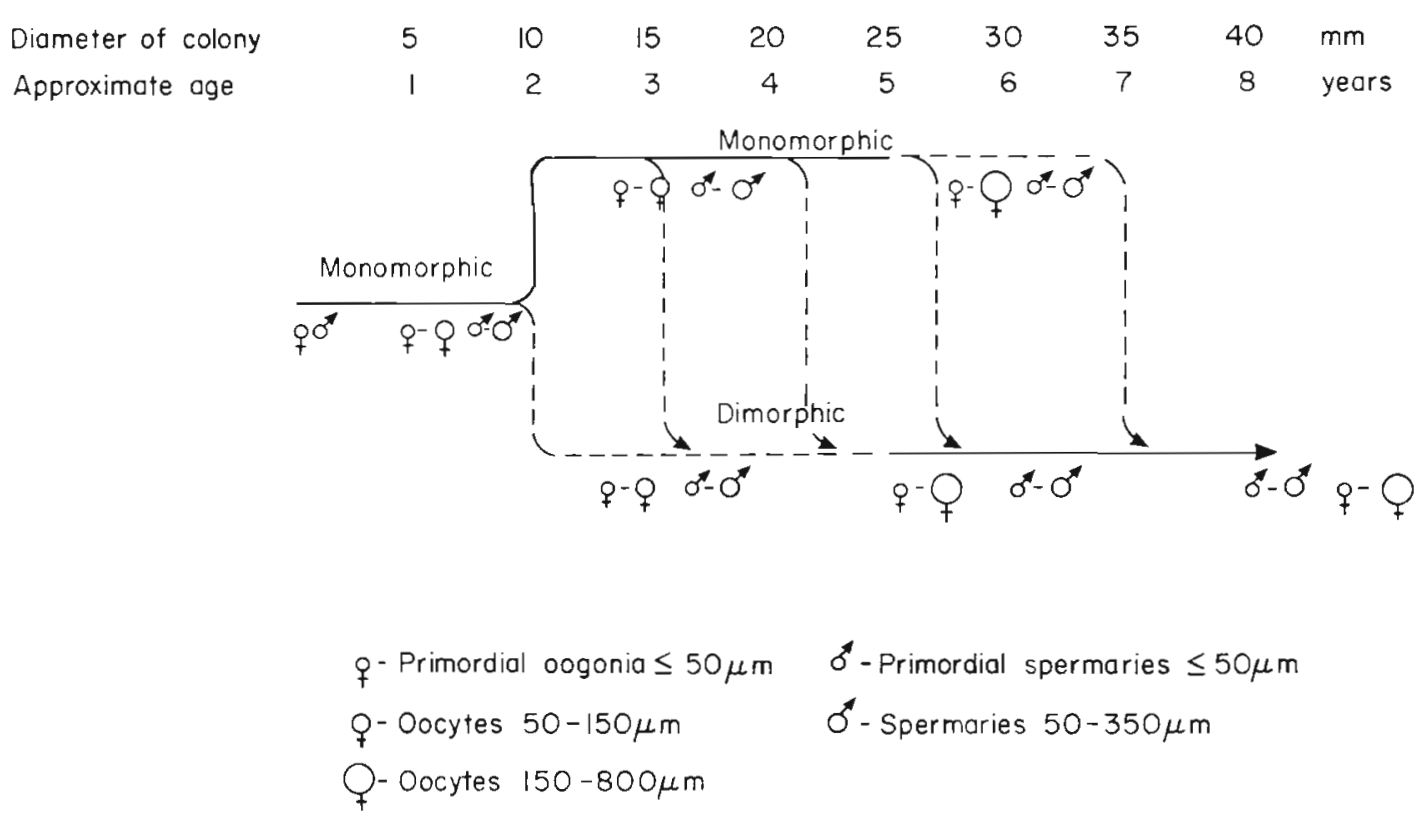

Fig. 5. Heteroxenia fuscescens. Relationship between size of monomorphic and dimorphic colonies and their gonad development

\section{LITERATURE CITED}

Bayer, F. M. (1973). Colonial organization in Octocorals. In: Boardman, R. S., Cheetham, A. H., Oliver, W. A., Jr (eds.) Animal colonies development and function through time. Dowden, Hutchinson \& Ross, Stroudsburg, Pennsylvania, p. 69-93

Bayer, F. M. (1981). Key to the genera of Octocorallia exclusive of Pennatulacea (Coelenterata: Anthozoa), with diagnosis of new taxa. Proc. biol. Soc. Wash. 94: 902-947

Benayahu, Y (1990). Reproduction and developmental pathways of Xeniidae (Octocorallia: Alcyanacea). Hydrobiologia (in press)

Benayahu, Y., Berner, T., Achituv, Y (1989). Development of planulae within mesogleal coat in the soft coral Heteroxenia fuscescens. Mar Biol. 100: 203-210

Benayahu, Y., Loya, Y (1986). Sexual reproduction of a soft coral: synchronous and brief annual spawning of Sarcophyton glaucum (Quoy and Gaimard, 1833). Biol. Bull. mar biol. Lab., Woods Hole 170: 32-42

Bock, S. (1938). The Alcyonarian genus Bathyalcyon. K. Sven. Vetenskapsakad. Handl. (Tredje Serien) 14: 1-54

Chornesky, E. A., Peters, E. C. (1987). Sexual reproduction and colony growth in the scleractinian coral Porites astreoides. Biol. Bull. mar. biol. Lab., Woods Hole 172: 161-177

Cylkowski, B. (1911). Untersuchungen über den Dimorphismus bei den Alcyonarien. Inaugural Dissertation, Breslau. p. $1-47$

This article was submitted to the editor
Gohar, H. A. F. (1940). The development of some Xeniidae (Alcyonaria). Publs mar. biol. Stn Ghardaqa 2: 27-118

Harvell, C. D., Grosberg, R. K. (1988). The timing of sexual maturity in clonal animals. Ecology 69: 1855-1864

Hickson, S. J. (1931). The Alcyonarian family Xeniidae. With a revision of the genera and species. Sci. Rep. Gt Barrier Reef Exped. 1928-1929, 4: 137-180

Hyman, L. H. (1940). The invertebrates: Protozoa through Ctenophora. McGraw Hill, New York

Samson, D. A., Werk, K. S. (1986). Size-dependent effects in the analysis of reproductive effort in plants. Am. Nat. 127 : $667-680$

Schlichter, D., Kremer, B. P. (1985). Metabolic competence of endocytobiotic dinoflagellates (zooxanthellae) in the soft coral Heteroxenia fuscescens. Endocyt. Cell Res. 2: 71- 82

Utinomi, H., Imahara, Y (1976). A new second species of dimorphic alcyonacean octocoral Minabea from the bays of Sagami and Suruga, with emendation of generic diagnosis. Publs Seto mar. biol. Lab. 23: 205-212

Verseveldt, J., Bayer, F. M. (1988). Revision of the genera Bellonella, Eleutherobia, Nidalia and Nidaliopsis (Octocorallia: Alcyoniidae and Nidaliidae), with description of two new genera. Zool. Verh., Leiden 245: 3-131

Yamazato, K., Sato, M., Yamashiro, H. (1981). Reproductive biology of an alcyonacean coral Lobophytum crassum Marenzeller Proc. 4th int. Symp. coral Reefs 2: 671-678 [Gomez, E. D. et al. (eds.) Marine Sciences Center, University of the Philippines, Quezon City]

Manuscript first received: December 15, 1989

Revised version accepted: March 14, 1990 